\title{
Effect of health education program on coping, and quality of life of Kidney recipients
}

\author{
Yoseria Attia Ameen Omar(1)Eman Shokry Abd Allah(2), Amany Rashad Abo \\ El-Seoud(3) and Maha Moussa Mohamed Moussa(4) \\ (1) Master of Science in Nursing, Faculty of Nursing-Ain Sh.ams University. \\ (2)Community Health Nursing Department, Faculty of Nursing, Zagazig, University, \\ (3) Community medicine Department, Faculty of Medicine, Zagazig University, . (4) \\ Family and Community Health Nursing Department, Faculty of Nursing- Port Said \\ University.
}

\begin{abstract}
Background: Renal transplantation is the best treatment option for the end-stage of renal failure, although it needs some changes in patient lifestyle. The aim was to evaluate the effectiveness of health education program on coping and quality of life (QoL) of kidney recipients. Subject and methods: This study was carried out in the kidney transplantation outpatient clinics at Nasr City Health Insurance Hospital using a quasi-experimental design with pre-post-follow-up assessments. The sample was 77 of patients after one year of the kidney transplantation surgery. The tool included Jalowiec Coping Scale (JCS) and the SF-12v2 health survey to assess the Quality of Life. The researchers designed the health education program based on needs assessment, and implemented it in small groups sessions their numbers 11 group and each group contain 7 patients, twice per week. The effect was evaluated immediate post test and at 3-month follow-up. The work lasted January to August 2014. Results: The mean score of the emotional element of Jalowiec scale increased at the follow-up phase reaching 67.8 compared with 65.4 at the pre-intervention phase $(p=0.01)$. Coping and QoL scores were inter-correlated weakly to moderately at the three phases, while the history of previous surgery was a significant positive predictor of Jalowiec emotional score, For mental QoL Jalowiec confrontive score was a significant negative predictor, whereas having a chronic disease and the score of emotional Jalowiec were significant positive predictors of the physical QoL score, and the working state, previous surgery, and the Jalowiec confrontive score were negative predictors. Conclusion, the educational intervention has a significant positive effect on patients' emotional coping, but not on their QoL. The recommendation implementing the program after modifications to give more focus on the use of various coping strategies, with longer follow-up evaluation.
\end{abstract}

Keywords: Health education program, Renal transplant, Coping, Quality of Life 


\section{INTRODUCTION}

Renal Replacement Therapy (RRT) is considered the best treatment option for end-stage renal failure (Williamson et al., 2010). The term describes the various renal replacement substitution treatments available for severe acute or chronic renal failure (Sabaté, 2011). In general, indications and timing of RRT include volume overload, acid-base imbalance, hyperkalemia, uremia, pericarditis, and encephalopathy (Alexander and Sehgal, 2009). People generally have more energy, a less restricted diet, and fewer complications with a renal transplant than if they stay on conventional dialysis, which would enhance their quality of life (Baum, 2011).

The concept of quality of life (QoL), with the constituents of human happiness or satisfaction, has been with people for centuries. Psychologists and sociologists have described QoL in terms of individuals' aspirations or expectations in life, and how well those aspirations and expectations are fulfilled (Spiridi et al., 2008). Thereafter, health-related QoL entered the scientific language as a term for describing the consequences, for individuals or groups, of having a chronic and/or life-threatening health problem or undergoing a particular treatment (Theofilou, 2011). The QoL framework is composed of five interrelated domains, which are health factors, social factors, major health events, major life events, and quality of life and related factors (Lew and Piraino, 2012).

Coping strategies serve to reduce the impact of stressful events, thus attenuating the emotional and somatic responses and making it more possible to maintain normal performance. Coping strategies are two kinds: problem-solving strategies and emotion reducing strategies (Gelder et al., 2010). Most people use various forms of coping in a stressful situation; however, problem-focused coping predominates when people feel that something constructive can be done, and emotion-focused coping predominates when people believe the stressful situation cannot be changed (Kuiper et al., 2012). Strong positive correlations were found between in renal transplant patients' use and effectiveness ratings for most coping strategies (Overholser, 2012).

Patient education is known to have many positive effects on patients with lifethreatening illnesses, including increased knowledge retention, improved pain management, decreased length of hospitalization, and improved patient adherence to 
the medical regimen. Describing the experience from the patient's point of view in unambiguous, concrete and objective terms facilitates coping by decreasing the differences between expectations and actual experience and by increasing the patients understanding of the experience (Wiegand, 2011). This is an essential role of nursing, and such education must be individualized for each patient with renal transplant (Ghezelijeh and Emami, 2009), with due understanding of patient's abilities, and priorities (Wang et al., 2013).

\section{Significance :}

Renal transplantation is considered the best therapy of renal failure as it is less expensive after the first year of transplantation than the hemodialysis, and it avoids the physiological changes and complications of dialysis. Kidney recipients must have a basic understanding of transplant-related concepts and of the terms concerning their condition and treatment. Hence, patient education is essential for this patient group.

\section{AIM OF THE STUDY:}

The aim of this study was to assess the effect of a health education program on coping and quality of life (QoL) of kidney recipients.

The research hypothesis: was that the implementation of a health education program tailored to renal transplant recipients' needs will lead to statistically significant improvements in their coping, and QoL.

\section{SUBJECTS AND METHODS:}

Setting: This study was carried out in the kidney transplantation outpatient clinics at Nasr City Health Insurance Hospital, the total numbers of kidney recipients who attended at the outpatient clinics are 3800 patients.

Research design The study design was a quasi-experimental design with pre-postfollow-up assessments.

\section{Subjects}

Any patient attending the study setting for renal transplantation during the time of the study was eligible for inclusion in the study sample if fulfilling the inclusion criteria of being 20 to 50 years old, within one year of the date of the kidney 
transplantation surgery, currently taking immunosuppressant, and willing to participate in the study. Patients residing outside greater Cairo and those physically or mentally unable to participate in the study were excluded. The sample size was calculated to detect an expected improvement in patients' scores of coping or QoL by $50 \%$ or more from a baseline level of $50 \%$ or less, at $95 \%$ confidence level and $80 \%$ study power. After compensation for a dropout rate of about $15 \%$, the required sample size was 77 patients. A consecutive sampling technique was used to recruit eligible patients who fulfill the criteria.

$$
\begin{aligned}
& 2 p q\left(z_{\alpha / 2}+z_{\beta}\right)^{2} \\
& n=\quad\left(p_{1}-p_{2}\right)^{2}
\end{aligned}
$$

Where:

$$
n=\text { sample size per group }
$$$$
p=\left(p_{1}+p_{2}\right) / 2
$$$$
q=1-p
$$

$z_{\alpha / 2}=1.96$

$z_{\beta}=0.84$

Data collection tools: The data collection tool was an interview questionnaire form based review of pertinent literature. The first section for patient's socio-demographic data as age, sex, education, job, smoking, etc., a second section for the medical history such as present illness duration, related hospitalizations, and other chronic diseases; in addition to questions about patient's compliance. The third section of the form consisted of Jalowiec Coping Scale (JCS) developed by Jalowiec et al. (1984) to measure the use of coping strategies.Scoring system It is composed of 35 questions classified into confrontative (14 items), emotional (11 items), and palliative (10 items) coping. The responses are on a 3-point Likert scale: "always," "sometimes," and "never," scored 2, 1, and 0 respectively. The scores of the items of each strategy were summed-up and means and standard deviations and medians were computed. A higher score means more use of the coping strategy.

This fourth section was for assessment of patient's Quality of Life using the SF$12 \mathrm{v} 2$ health survey. This is short 12-question survey designed to measure patient's 
quality of life in relation to health-related dysfunctions in several areas of renal transplant recipient activities as sleep, rest, eating, home management, reaction to stress, mobility, emotional behavior, social interaction, and communication. The tool measures physical and mental QOL.The scoring system is done according to tool guidelines so that a higher score indicates better QoL (Quality Metric, 2014). The development of the tools was under supervisors' guidance and experts' opinions were considered for validation. The tools were formulated according to their recommendations.

\section{Pilot study}

A pilot study was carried out on ten patients to test the tool for applicability and feasibility. The time for filling-in the tool was 25-30 minutes for the interview questionnaire sheet for each patient. Based on the results of the pilot study, the necessary modifications were done and the finalized forms were developed. The patients in the pilot sample were not included in the sample of the main research work. The pilot also served to assess the reliability of the scales used through measuring their internal consistency. The reliability of both scales was high, with Cronbach alpha coefficients 0.800 for Jalowiec scale and 0.916 for the QoL scale.

\section{Fieldwork}

The fieldwork of the study was during the period from the beginning of January 2014 to the end of August 2014 through assessment, planning, implementation, and evaluation phases.

Assessment phase: Data were collected through individual interviewing in the study setting. A maximum of four patients were recruited per day. The data collected served as baseline for post-intervention comparisons, and helped the researchers to determine the educational needs of the patients for construction of the program.

Planning phase: Using the assessment data, in addition to pertinent literature, the researchers designed the health education program and prepared a booklet for use by participants. The program general objective was to improve patients' abilities to use different coping strategies, which would help improve their QoL. It involved theoretical background as well as practical exercises. 
Implementation phase: The researchers administered the educational program in the study setting in 11 groups, each group consists of 7 patients, 2 days per week. The program was divided into five 45-minute sessions. Various teaching methods were used such as mini-lectures, open discussions, questions and answering, as well as role playing and simulations. The illustrated booklet prepared by the researcher was distributed to participants for reference.

Evaluation phase: During this phase, the researcher evaluated the effectiveness of the educational program through immediate posttest and follow-up test after 3 months using the same data collection tools.

\section{Administrative and ethical considerations:}

Necessary official permissions were obtained from the pertinent authorities to carry out the study. The study protocol was approved by the research and ethics committee of the Faculty of Nursing at Port Said University. Informed consents were obtained from every patient before recruitment and after a clear explanation of the study objectives and procedures. Patients were informed of their rights to refuse or withdraw at any time with no reasons and no consequences. They were also reassured that all the gathered information would be confidential and used for research purpose only. The study maneuver could have any actual or potential harmful effects on participants.

Statistical analysis: Data entry and statistical analysis were done using SPSS 20.0 statistical software package. Cronbach alpha coefficient was calculated to assess the reliability of the scales. Spearman rank correlation was used for assessment of the inter-relationships among quantitative variables and ranked ones. In order to identify the independent predictors of coping and QoL scores, multiple linear regression analysis was used after testing for normality, and homoscedasticity, and analysis of variance for the full regression models was done. Statistical significance was considered at $\mathrm{p}$-value $<0.05$.

\section{RESULTS:}

Table (1) shows that the patients' age ranged between 8 and 54 years with a mean 35.4 years. The majority was males $(81.8 \%)$, married $(66.2 \%)$, working $(71.1 \%)$, and 
having sufficient income (79.2\%). Slightly less than half of the patients had intermediate education (48.1\%), while $35.1 \%$ had university education. The sample was almost equally distributed in rural (51.9\%) and urban $(48.1 \%)$ residence.

Concerning the medical history of the patients, Table (2) illustrates that a majority had their graft for one or more months (77.9\%), with a median of 1 month. Also, the majority had previous hospitalization (87\%) and surgery for their renal disease (77.9\%) which was all for renal transplantation. Slightly more than half of the patients had concomitant chronic diseases (54.5\%), mostly hypertension (50.6\%) and diabetes $(24.7 \%)$. As regards the smoking habit, the majority (72.7\%) was non-smoking. Only a few of the patients had family history of similar disease (5.2\%), and only $1(1.3 \%)$ of renal transplantation. As regards pre-operative instructions, only $11.7 \%$ of the patients had all needed instructions.

Table (3) demonstrates statistically significant improvements in patients' knowledge about their medications from a pre-intervention level of $85.7 \%$ to $98.7 \%$ at the postintervention phase, and $100.0 \%$ at the follow-up phase. Meanwhile, although patients' compliance with medications intake and with instructions improved, the differences did not reach statistical significance.

Table (4) illustrates the changes in patients' coping and quality of life (QoL) throughout the study phases. It is evident that the only statistically significant change was in the emotional element of Jalowiec coping scale $(\mathrm{p}=0.01)$. The mean score of this element increased only at the follow-up phase reaching 67.8 compared with 65.4 at the pre-intervention phase.

Table (5) illustrates that the coping and QoL scales were inter-correlated weakly to moderately at the three phases. Meanwhile, the mental QoL was negatively and weakly correlated to confrontive coping and positively to palliative and emotional coping.

Table (6) demonstrates that patient's education has statistically significant negative correlation with confrontive coping at the pre and post-intervention phases. Meanwhile, patients' age correlated weakly and negatively with confrontive coping at the post-intervention phase. The graft duration correlated weakly and positively with emotional coping at the pre-intervention phase. The number of instructions received 
correlated weakly and positively with mental QoL at the pre-intervention phase, and with physical QoL at the follow-up phase.

Table (7) displays the best fitting multiple regression model for patients' Jalowiec scores. Concerning Jalowiec confrontive score, only patient's education was a statistically significant independent negative predictor of this score. The model explains $16 \%$ of the variation in this score. As regards Jalowiec emotional score, the table indicates that the history of previous surgery is a statistically significant independent positive predictor of this score, while the family history of similar disease is a negative predictor. The model explains only $5 \%$ of the variation in this coping score.

The best fitting multiple regression model for patients' mental QoL score (Table 8) shows that the Jalowiec confrontive score is the only statistically significant independent negative predictor of this score. The model explains $10 \%$ of the variation in the mental QoL score. As for the physical QoL score, having a chronic disease and the score of emotional Jalowiec are the statistically significant independent positive predictors of this score. Meanwhile, the working state, previous surgery, and the Jalowiec confrontive score are negative predictors. The Jalowiec confrontive score is the most influential factor as indicated by its standardized beta coefficient. The model explains $24 \%$ of the variation in the physical QoL score. 
Table 1: Socio-demographic characteristics of patients studied $(n=77)$

\begin{tabular}{|c|c|c|}
\hline Socio-demographic characteristics & Frequency & Percent \\
\hline Age: & & \\
\hline$<40$ & 44 & 57.1 \\
\hline $40+$ & 33 & 42.9 \\
\hline Range & \multicolumn{2}{|l|}{$8.0-50.0$} \\
\hline Mean \pm SD & \multicolumn{2}{|l|}{$35.4 \pm 11.1$} \\
\hline Median & \multicolumn{2}{|l|}{37.0} \\
\hline \multicolumn{3}{|l|}{ Gender: } \\
\hline Male & 63 & 81.8 \\
\hline Female & 14 & 18.2 \\
\hline \multicolumn{3}{|l|}{ Marital status: } \\
\hline Unmarried & 26 & 33.8 \\
\hline Married & 51 & 66.2 \\
\hline \multicolumn{3}{|l|}{ Education: } \\
\hline Basic & 13 & 16.9 \\
\hline Intermediate & 37 & 48.1 \\
\hline University & 27 & 35.1 \\
\hline \multicolumn{3}{|l|}{ Job: } \\
\hline Unemployed & 23 & 29.9 \\
\hline Working & 54 & 70.1 \\
\hline \multicolumn{3}{|l|}{ Residence: } \\
\hline Rural & 40 & 51.9 \\
\hline Urban & 37 & 48.1 \\
\hline \multicolumn{3}{|l|}{ Income: } \\
\hline Insufficient & 16 & 20.8 \\
\hline Sufficient & 61 & 79.2 \\
\hline
\end{tabular}


Table 2: Medical and family history of patients studied $(n=77)$

\begin{tabular}{|c|c|c|}
\hline Medical and family history & Frequency & Percent \\
\hline \multicolumn{3}{|l|}{ Duration of graft (months): } \\
\hline$<1$ & 17 & 22.1 \\
\hline $1+$ & 60 & 77.9 \\
\hline Range & $<1-6$ & \\
\hline Mean \pm SD & $1.0 \pm 0.9$ & \\
\hline Median & 1 & \\
\hline \multicolumn{3}{|l|}{ Previous history of: } \\
\hline Hospitalization & 67 & 87.0 \\
\hline Surgery for renal disease & 60 & 77.9 \\
\hline Renal transplantation & 60 & 77.9 \\
\hline Have chronic diseases & 42 & 54.5 \\
\hline \multicolumn{3}{|l|}{ Diseases: } \\
\hline Hypertension & 39 & 50.6 \\
\hline Diabetes & 19 & 24.7 \\
\hline Hepatic & 7 & 9.1 \\
\hline Psoriasis & 1 & 1.3 \\
\hline \multicolumn{3}{|l|}{ Number of diseases } \\
\hline Range & \multicolumn{2}{|l|}{$0-3$} \\
\hline Mean \pm SD & \multicolumn{2}{|l|}{$0.9 \pm 0.9$} \\
\hline Median & \multicolumn{2}{|l|}{1} \\
\hline \multicolumn{3}{|l|}{ Smoking; } \\
\hline None & 86 & 72.7 \\
\hline Ex-smoker & 17 & 22.1 \\
\hline Current & 4 & 5.2 \\
\hline \multicolumn{3}{|l|}{ Family history of: } \\
\hline Similar disease & 4 & 5.2 \\
\hline Renal transplant & 1 & 1.3 \\
\hline \multicolumn{3}{|l|}{ Had all pre-operative instructions: } \\
\hline No & 68 & 88.3 \\
\hline Yes & 9 & 11.7 \\
\hline
\end{tabular}

(@) Not mutually exclusive 
Table 3: Patients' compliance throughout intervention

\begin{tabular}{|c|c|c|c|c|c|c|c|c|}
\hline \multirow{3}{*}{$\begin{array}{l}\text { Compliance and body } \\
\text { mass index }\end{array}$} & \multicolumn{6}{|c|}{ Time } & \multirow{3}{*}{$\begin{array}{l}\mathrm{X}^{2} \\
(\mathrm{P}- \\
\text { value }) \\
\text { Pre-post }\end{array}$} & \multirow{3}{*}{$\begin{array}{l}\mathrm{X}^{2} \\
(\mathrm{P}- \\
\text { value }) \\
\text { Pre-FU }\end{array}$} \\
\hline & \multicolumn{2}{|c|}{$\begin{array}{l}\text { Pre } \\
(n=77)\end{array}$} & \multicolumn{2}{|c|}{$\begin{array}{l}\text { Post } \\
(\mathrm{n}=77)\end{array}$} & \multicolumn{2}{|c|}{$\begin{array}{l}\text { FU } \\
(\mathrm{n}=77)\end{array}$} & & \\
\hline & No. & & & $\%$ & No. & $\%$ & & \\
\hline Know all medications & 66 & 85.7 & 76 & 98.7 & 77 & 100.0 & $\begin{array}{l}9.04 \\
(0.003 *)\end{array}$ & $\begin{array}{l}11.85 \\
(0.001 *)\end{array}$ \\
\hline $\begin{array}{l}\text { Comply with } \\
\text { medications intake }\end{array}$ & 64 & 83.1 & 70 & 90.9 & 71 & 92.2 & $\begin{array}{l}2.07 \\
(0.15)\end{array}$ & $\begin{array}{l}2.94 \\
(0.09)\end{array}$ \\
\hline $\begin{array}{l}\text { Comply with } \\
\text { instructions }\end{array}$ & 74 & 96.1 & 75 & 97.4 & 76 & 98.7 & $\begin{array}{l}\text { Fisher } \\
(1.00)\end{array}$ & $\begin{array}{l}\text { Fisher } \\
(0.62)\end{array}$ \\
\hline
\end{tabular}

(*) Statistically significant at $p<0.05$

Table 4: Patients' coping (Jalowiec) and Quality of Life (QOL) throughout intervention

\begin{tabular}{|c|c|c|c|c|c|c|c|c|}
\hline \multirow{3}{*}{$\begin{array}{l}\text { Coping } \\
\text { and QOL }\end{array}$} & \multicolumn{6}{|l|}{ Time } & \multirow{3}{*}{$\begin{array}{l}\text { Kruskal } \\
\text { Wallis } \\
\text { test }\end{array}$} & \multirow{3}{*}{$\begin{array}{l}\mathrm{p}- \\
\text { value }\end{array}$} \\
\hline & \multicolumn{2}{|l|}{ Pre $(n=77)$} & \multicolumn{2}{|l|}{ Post $(n=77)$} & \multicolumn{2}{|l|}{$\mathrm{FU}(\mathrm{n}=77)$} & & \\
\hline & Mean \pm SD & Median & Mean \pm SD & Median & Mean \pm SD & Median & & \\
\hline \multicolumn{9}{|l|}{ Jalowiec: } \\
\hline Confrontative & $35.1 \pm 14.6$ & 35.70 & $30.5 \pm 13.7$ & 28.60 & $29.8 \pm 13.1$ & 28.60 & 5.15 & 0.08 \\
\hline Emotional & $65.4 \pm 8.4$ & 63.60 & $65.0 \pm 7.2$ & 68.20 & $67.8 \pm 7.2$ & 68.20 & 9.01 & $0.01 *$ \\
\hline Palliative & $60.1 \pm 12.9$ & 60.00 & $59.6 \pm 10.7$ & 60.00 & $60.3 \pm 10.4$ & 60.00 & 0.12 & 0.94 \\
\hline \multicolumn{9}{|l|}{ QOL SF-12: } \\
\hline Mental & $61.0 \pm 4.8$ & 60.00 & $61.9 \pm 4.4$ & 63.30 & $61.4 \pm 4.0$ & 60.00 & 1.60 & 0.45 \\
\hline Physical & $55.5 \pm 6.7$ & 56.70 & $55.1 \pm 7.2$ & 56.70 & $55.6 \pm 6.7$ & 56.70 & 0.30 & 0.86 \\
\hline
\end{tabular}

(*) Statistically significant at $p<0.05$ 
Table 5: Correlation matrix of patients' knowledge, coping and QOL scores throughout the intervention

\begin{tabular}{|c|c|c|c|c|c|}
\hline & Spearman's & correlation & efficient & & \\
\hline & $\begin{array}{l}\text { Jalowiec } \\
\text { confrontive }\end{array}$ & $\begin{array}{l}\text { Jalowiec } \\
\text { Emotional }\end{array}$ & $\begin{array}{l}\text { Jalowiec } \\
\text { Palliative }\end{array}$ & $\begin{array}{l}\text { QOL } \\
\text { Mental }\end{array}$ & $\begin{array}{l}\text { QOL } \\
\text { Physical }\end{array}$ \\
\hline PRE & & & & & \\
\hline Jalowiec: & & & & & \\
\hline Confrontive & & & & & \\
\hline Emotional & 0.04 & & & & \\
\hline Palliative & $.275^{*}$ & $.487 * *$ & & & \\
\hline QoL: & & & & & \\
\hline QoL mental & $-.277 *$ & 0.04 & -0.03 & & \\
\hline QoL physical & $-.274 *$ & 0.08 & 0.02 & $.637 * *$ & \\
\hline POST & & & & & \\
\hline Jalowiec: & & & & & \\
\hline Confrontive & & & & & \\
\hline Emotional & $.248 *$ & & & & \\
\hline Palliative & $.320 * *$ & $.483 * *$ & & & \\
\hline QoL: & & & & & \\
\hline QoL mental & -0.22 & 0.11 & 0.06 & & \\
\hline QoL physical & $-.342 * *$ & 0.18 & -0.04 & $.566 * *$ & \\
\hline FU & & & & & \\
\hline Jalowiec: & & & & & \\
\hline Confrontive & & & & & \\
\hline Emotional & $.370 * *$ & & & & \\
\hline Palliative & 0.22 & $.538 * *$ & & & \\
\hline QoL: & & & & & \\
\hline QoL mental & -0.22 & 0.02 & -0.02 & & \\
\hline QoL physical & $-.298 * *$ & $.224^{*}$ & -0.01 & $.416 * *$ & \\
\hline
\end{tabular}

(*) Statistically significant at $p<0.05$ (**) Statistically significant at $p<0.01$ 
Table 6: Correlation between patients' knowledge, coping and QOL scores throughout the intervention and their personal characteristics

\begin{tabular}{|c|c|c|c|c|c|}
\hline & \multicolumn{5}{|c|}{ Spearman's rank correlation coefficient } \\
\hline & $\begin{array}{l}\text { Jalowiec } \\
\text { confrontive }\end{array}$ & $\begin{array}{l}\text { Jalowiec } \\
\text { Emotional }\end{array}$ & $\begin{array}{l}\text { Jalowiec } \\
\text { Palliative }\end{array}$ & $\begin{array}{l}\text { QOL } \\
\text { Mental }\end{array}$ & $\begin{array}{l}\text { QOL } \\
\text { Physical }\end{array}$ \\
\hline \multicolumn{6}{|l|}{ PRE } \\
\hline Age & -0.12 & -0.04 & -0.05 & -0.03 & 0.06 \\
\hline Education & $-.410 * *$ & 0.13 & 0.03 & 0.12 & 0.15 \\
\hline Graft duration & -0.13 & $.251 *$ & 0.05 & -0.09 & 0.00 \\
\hline No. of diseases & -0.12 & 0.09 & -0.12 & -0.03 & 0.12 \\
\hline No. of instructions & -0.16 & -0.11 & -0.20 & $.228 *$ & 0.19 \\
\hline \multicolumn{6}{|l|}{ POST } \\
\hline Age & $-.323 * *$ & -0.19 & -0.14 & 0.02 & 0.04 \\
\hline Education & $-.315 * *$ & -0.13 & -0.01 & 0.16 & 0.06 \\
\hline Graft duration & 0.12 & 0.11 & 0.10 & -0.11 & -0.05 \\
\hline No. of diseases & 0.04 & 0.02 & 0.07 & 0.07 & 0.08 \\
\hline No. of instructions & 0.03 & -0.03 & -0.11 & -0.07 & 0.09 \\
\hline \multicolumn{6}{|l|}{ FU } \\
\hline Age & 0.04 & -0.01 & -0.04 & -0.07 & 0.03 \\
\hline Education & -0.20 & 0.00 & 0.04 & 0.01 & 0.06 \\
\hline Graft duration & 0.08 & 0.10 & 0.07 & -0.12 & -0.19 \\
\hline No. of diseases & -0.06 & 0.04 & 0.02 & -0.02 & 0.16 \\
\hline No. of instructions & -0.22 & 0.00 & -0.07 & -0.04 & $.309 * *$ \\
\hline
\end{tabular}


Table 7: Best fitting multiple linear regression model for the Jalowiec scores

\begin{tabular}{|c|c|c|c|c|c|c|c|}
\hline & \multicolumn{2}{|c|}{$\begin{array}{l}\text { Unstandardized } \\
\text { Coefficients }\end{array}$} & \multirow{2}{*}{$\begin{array}{l}\text { Standardized } \\
\text { Coefficients }\end{array}$} & \multirow[t]{2}{*}{ t-test } & \multirow{2}{*}{ p-value } & \multicolumn{2}{|c|}{$\begin{array}{l}95 \% \text { Confidence } \\
\text { Interval for B }\end{array}$} \\
\hline & $\mathrm{B}$ & Std. Error & & & & Lower & Upper \\
\hline \multicolumn{8}{|c|}{ Jalowiec confrontive score } \\
\hline Constant & 63.636 & 5.821 & & 10.932 & $<0.001$ & 52.135 & 75.138 \\
\hline Education & -5.574 & 1.306 & -0.323 & -4.269 & $<0.001$ & -8.155 & -2.994 \\
\hline \multicolumn{8}{|c|}{$\begin{array}{l}\text { r-square }=0.16 \quad \text { Model ANOVA: } \mathrm{F}=14.69, \mathrm{p}<0.001 \\
\text { Variables entered and excluded: age, gender, marital status, job, residence, smoking, } \\
\text { duration of illness, chronic diseases, previous surgery, family history, intervention }\end{array}$} \\
\hline \multicolumn{8}{|c|}{ Jalowiec emotional score } \\
\hline Constant & 62.294 & 1.299 & & 47.971 & $<0.001$ & 59.728 & 64.86 \\
\hline Previous surgery & 4.048 & 1.48 & 0.216 & 2.736 & 0.007 & 1.125 & 6.971 \\
\hline Family history & -6.492 & 3.172 & -0.162 & -2.047 & 0.042 & -12.758 & -0.226 \\
\hline \multicolumn{8}{|c|}{$\begin{array}{l}\text { Variables entered and excluded: age, gender, education, marital status, job, residence, } \\
\text { smoking, duration of illness, chronic diseases, previous surgery, intervention, } \\
\text { knowledge score, practice score, intervention }\end{array}$} \\
\hline
\end{tabular}


Table 8: Best fitting multiple linear regression model for the Mental QOL score

\begin{tabular}{|c|c|c|c|c|c|c|c|}
\hline & \multicolumn{2}{|c|}{$\begin{array}{l}\text { Unstandardized } \\
\text { Coefficients }\end{array}$} & \multirow{2}{*}{$\begin{array}{l}\text { Standardized } \\
\text { Coefficients }\end{array}$} & \multirow[t]{2}{*}{ t-test } & \multirow[t]{2}{*}{ p-value } & \multicolumn{2}{|c|}{$\begin{array}{l}95 \% \text { Confidence } \\
\text { Interval for B }\end{array}$} \\
\hline & B & Std. Error & & & & Lower & Upper \\
\hline \multicolumn{8}{|l|}{ Mental QoL score } \\
\hline Constant & 64.734 & 0.889 & & 72.807 & $<0.001$ & 62.977 & 66.49 \\
\hline $\begin{array}{l}\text { Jalowiec confrontive } \\
\text { score }\end{array}$ & -0.1 & 0.025 & -0.311 & -4.031 & $<0.001$ & -0.149 & -0.051 \\
\hline r-square $=0.10$ & \multicolumn{7}{|c|}{ Model ANOVA: $\mathrm{F}=16.25, \mathrm{p}<0.001$} \\
\hline \multicolumn{8}{|c|}{$\begin{array}{l}\text { Variables entered and excluded: age, gender, education, marital status, job, residence, } \\
\text { smoking, duration of illness, chronic diseases, previous surgery, intervention, } \\
\text { knowledge score, practice score, Jalowiec emotional score, Jalowiec palliative score, } \\
\text { intervention }\end{array}$} \\
\hline \multicolumn{8}{|l|}{ Physical QoL score } \\
\hline Constant & 56.388 & 4.798 & & 11.753 & $<0.001$ & 46.908 & 65.869 \\
\hline Working & -4.981 & 1.155 & -0.33 & -4.314 & $<0.001$ & -7.263 & -2.699 \\
\hline Previous surgery & -4.307 & 1.288 & -0.259 & -3.343 & 0.001 & -6.853 & -1.762 \\
\hline Chronic disease & 3.823 & 1.111 & 0.276 & 3.441 & 0.001 & 1.628 & 6.018 \\
\hline $\begin{array}{l}\text { Jalowiec confrontive } \\
\text { score }\end{array}$ & -0.168 & 0.035 & -0.348 & -4.827 & $<0.001$ & -0.237 & -0.099 \\
\hline $\begin{array}{l}\text { Jalowiec emotional } \\
\text { score }\end{array}$ & 0.217 & 0.065 & 0.244 & 3.318 & 0.001 & 0.088 & 0.346 \\
\hline
\end{tabular}


r-square=0.24 Model ANOVA: F=10.71, p<0.001

Variables entered and excluded: age, gender, education, marital status, residence, smoking, duration of illness, intervention, knowledge score, practice score, Jalowiec palliative score, intervention

\section{DISCUSSION:}

This study examined the research hypothesis that implementing a health education program for renal transplant patients would improve their coping and QoL. The results a slight positive effect of the educational program on patients' coping and on their QoL, which would lead to partial acceptance of the research hypothesis.

According to the present study results, the majority of the patients had instructions about the aim of the operation, hospital stay, and postoperative follow-up, as well as the instructions about the skills to be done after surgery, the possible complications, and wound care. This might explain the findings that a great majority of these patients knew all their medications correctly and were compliant with their intake. Moreover, all patients were compliant with instructions. Such compliance is of great importance in the success of renal transplantation, and thus should be closely monitored and fostered by the health care providers. In congruence with this, a study in France emphasized the importance of a multi-disciplinary team approach in transplant care (Chehade et al, 2015). Moreover, Müller et al (2010) in a study in Germany mentioned that Psychological risk factors of kidney transplant patients mentioned that the majority of the patients received instructions and guidelines regarding pre and post-operation care.

The present study investigated the effect of the nursing intervention on patients' QoL as well as the coping strategies they were using. The study results could not reveal any significant changes in patients' QoL scores either at the post or at the follow-up phases. This might be attributed to the short time interval of the intervention. In fact, a follow-up duration of three months might not be long enough to effect a significant change in patients' QoL. In congruence with this explanation, a recent study in Mexico examining the QoL of transplant patients revealed significant improvements in their QoL but only after 6-12 months of follow-up (Álvarez-Rangel et al., 2015). 
According to the present study findings, there were significant correlations between patients' scores of physical and mental QoL. This is quite expected since the physical status of the patient has a major influence on his/her mental and psychological status. This study finding is in agreement with the study of White-Williams et al (2014) who demonstrated a positive correlation between mental and physical QoL of transplant patients.

The change in patients' physical QoL scores in the current study were not independently influenced by the intervention. However, other factors were significantly related to this score. Thus, the QoL scores were significantly higher among patients having a concomitant chronic disease and having higher score of emotional coping. Conversely, the QoL scores were significantly lower among those patients who are employed, who had pervious surgery, and who had higher confrontive coping scores. The relation with employment may be explained by that employed patients may be pre-occupied with the problems of return to work, which might have a negative impact on their QoL.

As for the positive effect of emotional coping on QoL among patients in the present study, it might be attributed to the comforting feelings this type of coping affords such as turning to religion, which is in agreement with the finding reported by Gurkan et al, 2015) in a study in Turkey. On the same line, the study of Grady (2014) demonstrated a positive correlation between Jalowiec emotional coping and the QoL of transplant patients. Meanwhile, and in agreement with the present study, Rehabsalen and Norrbacka (2012) found no significant correlation between palliative coping and QoL.

As regards the effect of the present study intervention on renal transplant patients' coping, the only significant change throughout the study phases was an increase in the mean score of the emotional element of Jalowiec coping scale. This is expected in the short-term follow-up period where patients are overwhelmed with various stressors related to the surgery, post-operative care, and anxiety about outcomes. In this situation, it is easier for them to resort to emotional coping, with more focus on spirituality and optimistic thinking. 
In congruence with this foregoing present study finding, a study in Iran demonstrated a higher tendency to use emotion-oriented coping strategies among ESRD patients to deal with various types of stressors (Parvan et al, 2015). Similar findings were also reported by Gill (2012) in a study in the United Kingdom, so that the author recommended that these patients need appropriate emotional care and support throughout the transplantation process. On the same line, Kathleen et al. (2013) found that the coping styles used by patients after transplant include optimism, seeking social support, having faith denial/avoidance, passivity, and fatalistic coping, rather than problem-oriented confrontive coping strategies.

The present study results have also revealed that the duration of illness had a significant positive correlation with the score of emotional coping. This indicates that the chronicity of the condition helps patient to better cope with it emotionally. This might be explained by the fact that the stressors experienced by the patient would diminish on the long run. In agreement with this, Harwood et al (2011) in a study in Canada and Tu et al (2014) in Taiwan, mentioned that the stress ESRD patients experience tends to decrease as the duration of illness increases.

\section{CONCLUSION AND RECOMMENDATIONS :}

In conclusion, the educational intervention has a significant positive effect on patients' emotional coping, but not on their QoL, which might be attributed to the short follow-up time. The confrontive coping score is a significant independent negative predictor of mental QoL score, while the emotional coping score is an independent positive predictor of physical QoL score. In view of the study findings, it is recommended to implement the educational program after modifications to give more focus on the use of various coping strategies, with longer follow-up evaluation. The study can be replicated using a randomized clinical trial design for better evidence. 


\section{REFERENCES :}

Alexander C., and Sehgal R. (2009): Barriers to cadaveric renal transplantation among blacks women and the poor. JAMA.; 280:1148 -1152.

Álvarez-Rangel L.E., Cruz-Santiago J., Meza-Jiménez, G., Bernáldez-Gómez G., Ledesma-González V.M., Camacho-Hernández F., Rodríguez-Rodríguez A., and Aguilar-Martínez C. (2015): [Modification of health-related quality of life in kidney transplant recipients]. [Article in Spanish] Rev Med Inst Mex Seguro Soc.;53 Suppl 1:S66-73.

Baum G. (2011): Weight gain and cardiovascular risk after organ transplantation. JPEN Parenter Enteral Nutr; 25:114-119.

Chehade H., Parvex P., Venetz J.P., Hadaya K., Typaldou S.A., Villard E., Vogeleisen C., Pilon N., Cachat F., and Pascual M. (2015): [Transition in kidney transplantation]. [Article in French] Rev Med Suisse.;11(462):456, 458-60.

Gelder M.G., Lopez-Ibor J.J., and Andreasen N.C. (2010): The New Oxford Textbook of Psychiatry Stress Related and Adjustment Disorders, Oxiford University Press, pp. 29-60.

Ghezelijeh T., and Emami A. (2009): Grounded Theory: Methodology and Philosophical Perspective. Nurse Researcher; 17(1): 15 - 23.

Gill P. (2012): Stressors and coping mechanisms in live-related renal transplantation. J Clin Nurs.;21(11-12):1622-31. doi: 10.1111/j.1365-2702.2012.04085.x.

Grady K.L. (2014): Predictors of perceived coping effectiveness in patients awaiting a heart transplant. Available from research Gat May 20, 2014

Gurkan A., Pakyuz S.C.., and Demir T. (2015): Stress Coping Strategies in Hemodialysis and Kidney Transplant Patients. Transplant Proc.;47(5):1392-7. doi: 10.1016/j.transproceed. 2015.05.022.

Harwood L., Wilson B., and Sontrop J. (2011): Sociodemographic differences in stressful experience and coping amongst adults with chronic kidney disease. J Adv Nurs.;67(8):1779-89. doi: 10.1111/j.1365-2648.2010.05605.x. Epub 2011 Mar 6. 
Jalowiec A., Murphy S.P., Powers M.J. (1984): Psychometric assessment of the Jalowiec Coping Scale. Nurs Res.; 33(3):157-61.

Kathleen U., Shaw M., Korecka M., and Kaplan B. (2013): Pharmacokinetics of Mycophenolic Acid in Renal Insufficiency.

Kuiper N.A., Martin R.A., and Olinger L.I. (2012): Coping, humour, stress and cognitive appraisals. Canadian Journal of Behavioral Science; 85: 81-96.

Lew S.Q., and Piraino B. (2012): Quality of life and psychological issues in peritoneal dialysis patients. Semin Dial; 18: 119-123.

Müller H., Gwinner W., Haltenhof H., Kornhuber J. and Juan Maler M. (2010): Psychological risk factors of kidney transplant patients Kidney International; 77: 833. doi:10.1038/ki.2010.48

Overholser J. C. (2012): Sense of humor when coping with life stress. Journal of Personality and Individual Differences; 73: 799-804.

Parvan K., Ahangar R., Hosseini F.A., Abdollahzadeh F., Ghojazadeh M., and Jasemi M. (2015): Coping methods to stress among patients on hemodialysis and peritoneal dialysis. Saudi J Kidney Dis Transpl.;26(2):255-62.

Quality Metric, (2014): An excerpt from the User's Manual for the SF-36v2 Health Survey, Second Edition, Chapter 13, p. 181

Qual Life Res. 2010 Mar;19(2):231-41. doi: 10.1007/s11136-009-9582-z. Epub 2010 Jan 22.Deriving SF-12v2 physical and mental health summary scores: a comparison of different scoring algorithms. 
Rehabsalen and Norrbacka (2012): (S2), Karolinska Universitetssjukhuset, Solna, Living with chronic kidney disease : Perceptions of illness and health-related quality of life, shiloh d. erdley, problem-solving therapy for depressed older hemodialysis patients: a pilot randomized trial for transplantation, 2013

Sabaté E. (2011): Adherence to long term therapies: evidence for action". World Health Organization. Geneva, 212 pp. ISBN 92-4-154599-2. [1] 2003

Spiridi S., Iakovakis A., and Kaprinis G. (2008): Renal insufficiency: Biological and psychosocial consequences. In: Psychiatry; 19: 28-34.

Sreevan R. (2007): A Guide to Mental Health and Psychiatric Nursing, $2^{\text {nd }}$ Ed., JAYPEE Brothers, pp. 208-214.

Theofilou P. (2011): Quality of life in end - stage renal disease: a qualitative analysis. Inter scientific health care; 3 (2): 70-80.

Tu H.Y., Shao J.H., Wu F.J., Chen S.H., and Chuang Y.H. (2014): Stressors and coping strategies of 20-45-year-old hemodialysis patients. Collegian.;21(3):185-92.

Wang F., Chen J., and Revicki D. (2013): Maintenance regimen study group healthrelated quality of life outcomes of sirolimus-treated kidney transplant patients: Results of a 2-year randomized clinical trial. Transplantation; 75(8): 1277-1285

White-Williams C., Grady K. L., Myers S., Naftel C., Wang E., Bourge R., and Rybarczyk B. (2014): the Relationships among Satisfaction with Social Support, Quality of Life, and Survival 5 to 10 Years after Heart Transplantation, J Cardiovasc Nurs. Author manuscript; available in PMC 2014 Sep 1.

Wiegand L. (2011): Advances in cardiac surgery valve repair. Critical Core Nurse; 23(2): 72-76, 78-91.

Williamson G., Chisholm M., Lance C., and Mulloy L. (2010): Development and validation of the immunosuppressant therapy adherence instrument (ITAS). Patient Education and Counselling; 59: 13-20. 


\section{تأثير برنامج تثقيف صحي على التكيف ، ونوعية حياة مرضى زراعة الكلى}

يسرية عطية أمين عمر ، إيمان شكرى عبد الله ، أمانى راثد أبو السعود، مها موسى محمد موسى

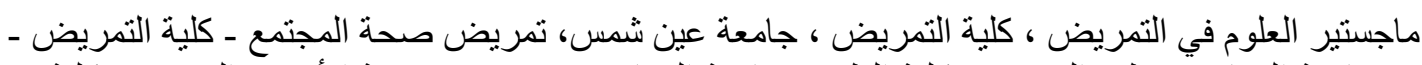

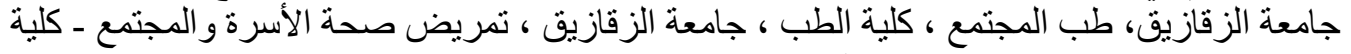
التمريض - جامعة بورسعيد.

\section{الخلاصة}

يستنبط من نتائج الدراسة أن تنفيذ برنامج تعليمي قائم على احتياجات مرضى زرع الكلى فعال في تحسين معرفتهم، واستر اتيجيات التكيف العاطفي. وتكيف المواجهة هو عامل تنبؤ سلبي لدرجة جودة الحياة العقلية، في حين أن التكيف العاطفي هو عامل تنبؤ إيجابي لجودة الحياة البدنية. و عدم وجود تأثير كبير ومباثر على جودة الحياة قد يكون راجعا إلى المدى القصير للمتابعة الذي يعد عامل القصور الرئيسي للار اسة.

التوصيات: نوصي الدراسة بتنفيذ برنامج تعليمي في مكان الدراسة و أماكن مماثلة بعد عمل بعض التعديلات لإعطاء مزيد من التركيز على استخدام استر اتيجيات التكيف المختلفة، مع طول مدة المتابعة. الكلمات المرشدة :برنامج تثقيف صحى،زرع الكلى و التكيف وجودة الحياة 